\title{
Synthesis of a New Conjugates of Imidazole with Beta Lactam Moiety and Evaluation of its Expanded Antibacterial Activity
}

\author{
SARMD D. NOORI*, MAZIN N. MOUSA and SHAKER A.N. AL-JADAAN \\ Department of Pharmaceutical Chemistry, College of Pharmacy, University of Basrah, Basrah, Iraq. \\ ${ }^{*}$ Corresponding author E-mail: sarmd18noori@gmail.com \\ http://dx.doi.org/10.13005/ojc/340535 \\ (Received: August 08, 2018; Accepted: October 06, 2018)

\begin{abstract}
Five compounds containing (2,4,5-triphenyl triphenyl-1H-) and azetidinone (beta-lactam) chemical structure of prepared compounds were characterized using FT-IR, ${ }^{1} \mathrm{H}-\mathrm{NMR}$ and elemental analysis. The antibacterial activity was evaluated using disc diffusion method that involve tow Gram positive (staph. aureus, E. Faecalis), two Gram negative (E. coli and K. pneumoniae), and one anaerobic bacteria (streptococcus. Pyogen). Different concentration of the prepared compounds has been used, and the obtained result were compared with standard (ceftazidime). Compound (5c) showed the best antibacterial activity against all bacterial species while $5 \mathrm{a}$ and $5 \mathrm{e}$ does not. Other
\end{abstract} \\ moiety were synthesized. The physical data and yield of synthesized compounds were recorded, the \\ compounds showed activity against some species.
}

Keywords: Antibacterial, Imidazole, Beta lactam, Aerobic, Anaerobic.

\section{INTRODUCTION}

Bacterial infection considered as one of the most serious problem that threaten the human life ${ }^{1}$. So that antibacterial field played an important role to save many human lives and contributed to the control of infectious diseases that considered as leading causes of human morbidity and mortality ${ }^{2}$ Unfortunately a considerable number and different types of the antibiotic agents are becoming less effective because of the spreading out of antimicrobial resistance. So there is an urgent need for the synthesis and development of new antibacterial agents that have the ability to eradicate the resistant strains ${ }^{3}$. That goal could be achieved by introduction of a new agents having more than one mechanism of action. So if the microorganism develops a resistance technique to a certain mechanism it will be still sensitive to the other one and it is less likely to develop resistance to the all mechanisms ${ }^{4}$. 2,4,5-Triphenyl$1 \mathrm{H}$-imidazole is a well-known compound containing five-member heterocyclic ring imidazole it is excessively investigated for their antimicrobial activity it is a versatile heterocyclic ring moiety having a wide range of biological activities ${ }^{5}$. Imidazole present in many antiprotozoal and antibacterial drugs such as tinidazole and metronidazole and in antifungal drugs such as miconazole ${ }^{6}$. Pharmaceutical applications of imidazole derivatives include, antibacterial 
activity, antifungal activity, anticancer activity, $\beta$-lactamase inhibitors activity, antiviral activity ${ }^{7-8}$. Azetidinone-2-on (beta-lactam) moiety is present in many important antibacterial agents. It presents in penicillins, cephalosporins, and in the monobactam antibiotics. These groups of antibiotics have the beta-lactam moiety, and they show a well-known and powerful antibacterial actions ${ }^{9}$. Both $(2,4,5-$ triphenyl-1H-imidazole and beta-lactam) possess a well-documented antimicrobial activity, Therefore, it is reasonable to synthesize products having the two groups with enhanced potential antimicrobial activity.

\section{MATERIAL AND METHODS}

All chemicals were supplied by Merck KGaA, (Germany), Melting points were determined by Electrothermal 9300 digital melting point apparatus (UK), temperature resolution within $0.1^{\circ} \mathrm{C}$. IR spectra of all compounds were recorded on FT-IR 8400S Shimadzu spectrophotometer (Japan) using $\mathrm{KBr}$ pellet. The ${ }^{1} \mathrm{H}-\mathrm{NMR}$ was recorded on Bruker Ultra shield $-400 \mathrm{MHz}$ spectrometer (Switzerland) in DMSO- $d_{6}$ by using TMS (Tetramethylsilane) as internal standard, chemical shifts were expressed as $\delta$ values (ppm). Elemental analysis of the prepared compounds was performed by Euro Vector EA 3000A (Italy) C, H, N, S elemental analyzer.

\section{Synthetic procedure of 2,4,5-triphenyl-1H- imidazole (1)}

In a $500 \mathrm{~mL}$ round bottom flask equipped with magnetic bar, benzil (50 mmol) (10.5 gm), benzaldehyde (50 mmol)(5.3 $\mathrm{gm})$ and excess ammonium acetate (250 mmol) (19.2 gm) was dissolved in $200 \mathrm{~mL}$ acetic acid. The mixture was refluxed on the hot plate for $4 \mathrm{~h}$ with stirring. The mixture then cooled to room temperature and it was filtered to remove any remaining precipitate. The filtrate was added into $250 \mathrm{~mL}$ of iced water and the $\mathrm{pH}$ of the mixture was neutralized with saturated sodium carbonate solution. The white precipitate was formed and it was collected by filtration under vacuum and recrystallized from ethanol and water. Yield 60\%, melting point $(287-290)^{\circ} \mathrm{C}$ (reported 292295) ${ }^{\circ} \mathrm{C} .{ }^{10}$

IR $\{\mathrm{KBR}\} \mathrm{cm}^{-1}: 3384[\mathrm{~N}-\mathrm{H}], 3074[\mathrm{C}-\mathrm{H}$ aromatic] 1455 [C=C aromatic]
Synthetic procedures of 2,4,5-triphenyl-1Himidazole-1-carbonylchloride (2)

Accurately weighted 2,4,5-triphenyl-1-Himidazole $(30 \mathrm{mmol})(8.8 \mathrm{gm})$ was dissolved in 70 $\mathrm{mL}$ of acetone in conical flask. To this solution (60 $\mathrm{mmol}$ ) (6.35 $\mathrm{gm}$ ) of anhydrous sodium carbonate was added. A dropping funnel was fitted to the conical flask and in the dropping funnel a solution of (10 mmol) (1.12 gm) of chloroacetylchloride was taken. A very slow drop wise addition of chloroacetylchloride solution was done. The reaction mixture was stirred for 5-6 h at cold condition. After 5-6 $\mathrm{h}$ excess of solvent and chloroacetylchloride was removed by distillation under reduced pressure and the residue was washed with aqueous sodium bicarbonate (5\%w/v, $50 \mathrm{~mL})$ and subsequently with cold water $50 \mathrm{~mL}$. The crude product was dried and recrystallization from ethanol to give white crystalline solid Yield 35\%, melting point ) 151-153) ${ }^{\circ} \mathrm{C}$

IR $\{\mathrm{KBR}\} \mathrm{cm}^{-1}: 3070$ [C-H aromatic], 2948 [C-H aliphatic], 1663 [C=O], 1578 [C=C aromatic], 744 [C-CL]

Synthetic procedure of hydrazine derivatives, 2-hydrazinyl-1-(2,4,5-triphenyl-1 H-imidazole -1-yl)ethan-1-one. (3)

In a conical flask, 2,4,5-triphenyl-1Himidazole -1- carbonyl chloride (10 mmol) (3.72 mg) was taken in acetone $(20 \mathrm{~mL})$ and hydrazine hydrate $(20 \mathrm{mmol}, 80 \%)(1 \mathrm{mg})$ was added to it. To this mixture $(20 \mathrm{mmol})(2.11 \mathrm{mg})$ of anhydrous sodium carbonate was added. The solution was stirred for stirred overnight, and then refluxed for 4 hour. The reaction mixture was cooled to room temperature and poured onto crushed ice with constant stirring. The solid formed was filtered and washed with water several times to remove excess of sodium carbonate. The product was recrystallized from ethanol: ether (1:3) to get off white powder.Yield $32 \%$ melting point (134-137) ${ }^{\circ} \mathrm{C}$.

IR $\{$ KBR $\} \mathrm{cm}^{-1}: 3481[\mathrm{~N}-\mathrm{H}], 3066[\mathrm{C}-\mathrm{H}$ aromatic], 2933 [C-H aliphatic], 1646 [C=O], 1545 $[\mathrm{C}=\mathrm{C}$ aromatic $]$,

Synthesis of Schiff base derivatives (2-hydrazinyl1-(2,4,5-triphenyl-1H-imidazole -1-yl)ethan-1-one) (4 a-e )

The compound 3 (10 mmol) $(3.70 \mathrm{mg})$ was dissolve in $25 \mathrm{~mL}$ of absolute ethanol. To which a 
toluene para sulfonic acid (10 mmol) $(1.72 \mathrm{mg})$ was added. benzaldehyde derivatives $(12 \mathrm{mmol})$ were added, and the reaction mixtures were refluxed for $6 \mathrm{~h}$ and left over night. A crystalline powder was formed which is collected by filtration under reduced pressure. The precipitate was washed with $5 \%$ sodium carbonate solution and then with D.W. The products were crystallized from hot ethanol. Yield, appearance in Table (1).

"4a": IR $\{K B R\} \mathrm{cm}^{-1}: 3316[\mathrm{~N}-\mathrm{H}], 3057$ [C-H aromatic], 2930 [ $\mathrm{C}-\mathrm{H}$ aliphatic], 1662 [C=O], $1609[\mathrm{C}=\mathrm{N}], 1500$ [C=C aromatic]

"4b": IR $\{\mathrm{KBR}\} \mathrm{cm}^{-1}: 3392[\mathrm{O}-\mathrm{H}], 3184$ [N-H], 2975 [C-H aliphatic], 1685 [C=O], 1645 [C=N], 1504 [C=C aromatic]

"4c": IR $\{\mathrm{KBR}\} \mathrm{cm}^{-1}: 3384[\mathrm{~N}-\mathrm{H}], 3028[\mathrm{C}-\mathrm{H}$ aromatic], 1685 [C=O], 1641 [C=N],

"4d": IR $\{K B R\} \mathrm{cm}^{-1}: 3300[\mathrm{~N}-\mathrm{H}], 3054$ [C-H aromatic], 2932 [C-H aliphatic], 1662 [C=O], $1609[\mathrm{C}=\mathrm{N}]$,

"4e" : IR $\{K B R\} \mathrm{cm}^{-1}: 3325[\mathrm{~N}-\mathrm{H}], 3028[\mathrm{C}-\mathrm{H}$ aromatic], 1701 [C=O], 1641 [C=N]

Synthesis of [3-chloro-1-((2-oxo-2-(2,4,5triphenyl-1H-imidazole -1-yl)ethyl)amino)-4phenylazetidin-2-one] derivatives (5 a-e )

A mixture of an appropriate Schiff base $(10 \mathrm{mmol})(4.56 \mathrm{mg})$, and triethylamine $(20 \mathrm{mmol})$ $(2.02 \mathrm{mg}$ ) was dissolved in dry 1,4-dioxane $25 \mathrm{~mL}$. To this mixture, a solution of $\alpha$-chloroacetyl chloride (15 mmol) (1.69 mg) was added drop by drop with vigorous stirring at room temperature for 30 minute. The reaction mixture was refluxed for $1 \mathrm{~h}$ and then the content was poured into crushed-ice. The solid precipitate was filtered and washed several times with water and recrystallized from hot ethanol, Yield, appearance in Table 1. All data of elemental analysis $[\mathrm{CHN}]$ in Table 2.

"5a" (R= H): melting point $(124-126)^{\circ} \mathrm{C}$; Yield $21 \%$; pale yellow powder; IR $\{\mathrm{KBR}\} \mathrm{cm}^{-1}: 3352[\mathrm{~N}-\mathrm{H}]$, 3051[C-H aromatic], 1670 [C=O], 2947 [ C-H aliphatic], 690 [C-Cl], 1442 [C=C aromatic], 1207 [C-N].

${ }^{1} \mathrm{H}-\mathrm{NMR}$ (DMSO) $\delta \mathrm{ppm} ; 4.33\left[\mathrm{~s}, \mathrm{~N}-\mathrm{CH}_{2}\right], 4.72$ [d, C-CH], 5.11 [d, Cl-CH], 7.28- 8.14 [m, Ar-H]. "5b" $(\mathrm{R}=\mathrm{OH})$ : melting point $(136-138)^{\circ} \mathrm{C}$; Yield $18 \%$; white crystalline ; IR $\{\mathrm{KBR}\} \mathrm{cm}^{-1}: 3350$ [O-H], 3309 [N-H], 3066 [C-H aromatic], 1674 [C=O], 2931 [C-H aliphatic], 1442 [C=C], 690 [C-Cl].

${ }^{1} \mathrm{H}-\mathrm{NMR}$ (DMSO) $\delta \mathrm{ppm:}$ 4.31[s, N-CH ], 4.78 [d, C-CH], 5.13 [d, CL-CH], 6.71-8.13 [m, Ar-H], $8.55[\mathrm{~s}, \mathrm{O}-\mathrm{H}]$.

"5c" (R=OCH $)$ : melting point $(139-143)^{\circ} \mathrm{C}$; Yield $26 \%$; white crystalline ; IR $\{\mathrm{KBR}\} \mathrm{cm}^{-1}: 3314$ [N-H], 3052 [C-H aromatic], 1674 [C=O], 2851 [C-H aliphatic], 690 [C-Cl], $1442[\mathrm{C}=\mathrm{C}]$.

${ }^{1} \mathrm{H}-\mathrm{NMR}$ (DMSO) $\delta$ ppm: 3.76 [s, O- $\left.\mathrm{CH}_{3}\right]$, $4.35\left[\mathrm{~s}, \mathrm{~N}-\mathrm{CH}_{2}\right], 4.76$ [d, C-CH], 5.15 [d, $\left.\mathrm{Cl}-\mathrm{CH}\right]$, 6.88-8.14 [ $\mathrm{m}, \mathrm{Ar}-\mathrm{H}]$.

"5d" (R=Cl): melting point (122-124) ${ }^{\circ} \mathrm{C}$; Yield $30 \%$; yellow - white powder; IR $\{\mathrm{KBR}\}$ $\mathrm{cm}^{-1}: 3396[\mathrm{~N}-\mathrm{H}], 3066[\mathrm{C}-\mathrm{H}$ aromatic], $2931[\mathrm{C}-\mathrm{H}$ aliphatic], 1675 [C=O], 960 [C-Cl].

${ }^{1} \mathrm{H}-\mathrm{NMR}$ (DMSO) $\delta \mathrm{ppm:} 4.33$ [s, $\mathrm{N}-\mathrm{CH}_{2}$ ], 4,78 [d, C-CH], 5.14 [d, $\mathrm{Cl}-\mathrm{CH}$ ], 7.34-8.23 [m, Ar-H].

"5e" (R=NO $)$ : melting point $(172-174)^{\circ} \mathrm{C}$; Yield $33 \%$; off-white powder ; ; IR $\{\mathrm{KBR}\} \mathrm{cm}^{-1}: 3368$ [N-H], 3051 [C-H aromatic], 2947 [C-H aliphatic].

${ }^{1} \mathrm{H}-\mathrm{NMR}$ (DMSO) $\delta \mathrm{ppm}: 4.02\left[\mathrm{~s}, \mathrm{~N}-\mathrm{CH}_{3}\right]$, 4.41 [d, C-CH], 4.82 [d, Cl-CH], 7.19-8.13 [m, $\mathrm{ArH}]$. The $\mathrm{CHN}$ analysis for the prepared compounds are with in \pm 0.5 which confirmed the proposed structure of the prepared compounds.

\section{Antibacterial activity}

The inhibition of bacterial growth under suitable conditions may be used for determining the therapeutic efficacy of synthesized compounds, this method showed the ability of the prepared compound to inhibition of bacterial growth or not in compare with standard antibacterial agent. The in-vitro antibacterial activities of the synthesized compounds were carried out by disc diffusion method using prepared disc technique. Antibacterial activity of newly synthesized compound "5a-e" were screened against bacterial strains E. coli (E. coli, MTCC 2961), Staphylococcus aureus (S. aureus, MTCC 3160), enterococcus facaels, Klebsiella pneumoniae (K. pneumoniae, MTCC 3040) and anaerobic bacteria (Streptococcus. Pyogen). The standard antibacterial compound was (ceftazidime). 




Scheme 1. Chemical Synthesis of the Desired Compounds

Table 1: Physical data, melting points and percent yield of compound (4a-e) compound

\begin{tabular}{|c|c|c|c|c|c|}
\hline Compound & $\begin{array}{l}\text { Molecular } \\
\text { formula }\end{array}$ & Yield \% & description & $\begin{array}{l}\text { Melting } \\
\text { point }{ }^{\circ} \mathrm{C}\end{array}$ & $\begin{array}{l}\text { Melting point } \\
\text { reported }^{10}\end{array}$ \\
\hline 1 & $\mathrm{C}_{21} \mathrm{H}_{16} \mathrm{~N}_{2}$ & 60 & White crystalline powder & 292-295 & $292-295^{\circ} \mathrm{C}$ \\
\hline 2 & $\mathrm{C}_{23} \mathrm{H}_{17} \mathrm{CIN}_{2} \mathrm{O}$ & 35 & White crystalline powder & $151-153$ & $155^{\circ} \mathrm{C}$ \\
\hline 3 & $\mathrm{C}_{23} \mathrm{H}_{20} \mathrm{~N}_{4} \mathrm{O}$ & 32 & Off-white powder & 134-137 & \\
\hline $4 a$ & $\mathrm{C}_{30} \mathrm{H}_{24} \mathrm{~N}_{4} \mathrm{O}$ & 43 & Yellow crystals, needle like shape & $135-138$ & - \\
\hline $4 b$ & $\mathrm{C}_{30} \mathrm{H}_{24} \mathrm{~N}_{4} \mathrm{O}_{2}$ & 35 & Reddish, crystal powder & 149-152 & - \\
\hline $4 c$ & $\mathrm{C}_{30} \mathrm{H}_{25} \mathrm{~N}_{4} \mathrm{O}_{2}$ & 48 & Yellow powder & $161-164$ & - \\
\hline $4 d$ & $\mathrm{C}_{30} \mathrm{H}_{23} \mathrm{CIN}_{4} \mathrm{O}$ & 60 & Dark yellow crystals flakes & $110-112$ & - \\
\hline $4 e$ & $\mathrm{C}_{30} \mathrm{H}_{23} \mathrm{~N}_{5} \mathrm{O}_{3}$ & 52 & $\begin{array}{l}\text { Deep orange color, } \\
\text { Needle like shape }\end{array}$ & 153-156 & - \\
\hline $5 a$ & $\mathrm{C}_{32} \mathrm{H}_{25} \mathrm{CIN}_{4} \mathrm{O}_{2}$ & 21 & Pale yellow - off white powder & $124-126$ & - \\
\hline $5 b$ & $\mathrm{C}_{32} \mathrm{H}_{25} \mathrm{CIN}_{4} \mathrm{O}_{3}$ & 18 & White crystalline powder & $136-138$ & - \\
\hline $5 c$ & $\mathrm{C}_{33} \mathrm{H}_{27} \mathrm{CIN}_{4} \mathrm{O}_{3}$ & 26 & White crystal powder & $139-142$ & - \\
\hline $5 d$ & $\mathrm{C}_{32} \mathrm{H}_{24} \mathrm{Cl}_{2} \mathrm{~N}_{4} \mathrm{O}_{2}$ & 30 & Yellow_white powder & $122-124$ & - \\
\hline $5 e$ & $\mathrm{C}_{32} \mathrm{H}_{24} \mathrm{CIN}_{5} \mathrm{O}_{4}$ & 33 & Off-white powder & $172-174$ & - \\
\hline
\end{tabular}

Table 2: CHN analysis of compound (5a-e)

\begin{tabular}{|c|c|c|c|c|c|c|}
\hline Compound 5 & Molecular formula & ular weight & & $\mathrm{C}$ & $\mathrm{H}$ & $\mathrm{N}$ \\
\hline \multirow[t]{2}{*}{ a } & \multirow{2}{*}{$\mathrm{C}_{32} \mathrm{H}_{25} \mathrm{CIN}_{4} \mathrm{O}_{2}$} & \multirow[t]{2}{*}{533} & Observed & 71.69 & 4.7 & 11 \\
\hline & & & Calculated & 72.04 & 4.69 & 10.5 \\
\hline \multirow[t]{2}{*}{ b } & \multirow{2}{*}{$\mathrm{C}_{32} \mathrm{H}_{25} \mathrm{CIN}_{4} \mathrm{O}_{3}$} & \multirow[t]{2}{*}{549} & Observed & 70.38 & 4.49 & 10.7 \\
\hline & & & Calculated & 69.94 & 4.55 & 10.2 \\
\hline \multirow[t]{2}{*}{ c } & \multirow[t]{2}{*}{$\mathrm{C}_{33} \mathrm{H}_{27} \mathrm{CIN}_{4} \mathrm{O}_{3}$} & \multirow[t]{2}{*}{563} & Observed & 70 & 4.67 & 10.33 \\
\hline & & & Calculated & 70.33 & 4.79 & 9.94 \\
\hline \multirow[t]{2}{*}{$d$} & \multirow{2}{*}{$\mathrm{C}_{32} \mathrm{H}_{24} \mathrm{Cl}_{2} \mathrm{~N}_{4} \mathrm{O}_{2}$} & \multirow[t]{2}{*}{567} & Observed & 67.95 & 4.17 & 10.12 \\
\hline & & & Calculated & 67.72 & 4.23 & 9.87 \\
\hline \multirow[t]{2}{*}{ e } & \multirow[t]{2}{*}{$\mathrm{C}_{32} \mathrm{H}_{24} \mathrm{CIN}_{5} \mathrm{O}_{4}$} & \multirow[t]{2}{*}{578} & Observed & 66.3 & 4.23 & 12.6 \\
\hline & & & Calculated & 66.43 & 4.15 & 12.11 \\
\hline
\end{tabular}


Each one of the aerobic bacterial species inoculated and spread on the surface of (Muller Hinton agar) by using a swap with uniform distribution pattern from different sides of petri dish to cover all upper surface of agar, six sterilized filter paper disc having diameter $(6 \mathrm{~mm})$, one disc represent the standard compound (ceftazidime), other five discs for prepared compound that immersed in specific concentration solutions of each compound "5a-e" applied with equal separated distance on the agar surface. Then incubate the prepared petri dish in a standardized incubation devise with setting temperature at $37^{\circ} \mathrm{C}$ for 24 hours. After incubation period, the inhibition zone diameters for each disc were recorded, then compared with standard compound (ceftazedime) inhibition diameter. The results summarized in Table 3.

Anaerobic bacteria (Streptococcus. Pyogen) was spread on (Muller Hinton agar) in the same manner as above, but the petri dish was incubated in anaerobic conditions using tightly closed jar that empty from oxygen by using candle inside the jar, then the flame of candle extinguish after oxygen consumption. incubate the jar in incubator device at temperature $37^{\circ} \mathrm{C}$ for $24 \mathrm{~h}$ the antibacterial activity against anaerobic bacteria was evaluated in compare with standard compound. Result summarized in Table 3.

Table 3: Antibacterial activity of the prepared compounds

\begin{tabular}{lcccccc}
\hline Compound & Concentration & \multicolumn{5}{c}{ Inhibition zone result diameter mm } \\
& $\mathrm{mg} / \mathrm{mL}$ & S. aureus & Klebsiella & E.coli & E.Fecalis & S. pyogen \\
\hline Standard & 0.5 & 22 & 12 & 10 & 15 & 24 \\
(CEFTAZIDIME) & 0.25 & 22 & 12 & 10 & 15 & 23 \\
& 0.125 & 22 & 12 & 10 & 15 & 23 \\
$5 \mathrm{a}$ & 0.5 & - & - & - & - & - \\
& 0.25 & - & - & - & - & - \\
& 0.125 & - & - & - & - & - \\
$5 \mathrm{~b}$ & 0.5 & - & 6 & 6 & - & 17 \\
& 0.25 & - & 6 & 2 & - & 13 \\
& 0.125 & - & - & - & - & - \\
$5 \mathrm{c}$ & 0.5 & 23 & 20 & 30 & 42 & 37 \\
& 0.25 & 19 & 18 & 25 & 30 & 30 \\
& 0.125 & 12 & 17 & 19 & 20 & 20 \\
$5 \mathrm{~d}$ & 0.5 & - & - & 15 & 20 & 8 \\
& 0.25 & - & - & 9 & 17 & - \\
& 0.125 & - & - & 7 & 13 & - \\
$5 \mathrm{~F}$ & 0.5 & - & - & - & - & - \\
& 0.25 & - & - & - & - & - \\
& 0.125 & - & - & - & - & - \\
\hline
\end{tabular}

\section{RESULT AND DISCUSSION}

A series of compound "5a-e" have been successfully synthesized. The disc diffusion method was performed to evaluate the antibacterial activity for each of prepared compound. all the synthesized compounds were characterized by IR, ${ }^{1} \mathrm{H}-\mathrm{NMR}$ and $\mathrm{CHN}$ analysis, which agreed well with the proposed structure of prepared compounds. aerobic bacterial species that used were, two Gram-negative (Enerococcus.coli and Klepsiella. pneumonia) and two Gram-positive (Staphylococcus. aureus and Enterococcus.faecalis) in addition to one anaerobic bacteria (Streptococcus. Pyogen). Compound "5a-e" showed variant antibacterial activity on the four aerobic bacterial species in compared to standard compound. Compound " $5 \mathrm{c}$ " showed the best antibacterial activity against all four aerobic bacterial species, and showed the ability to effect on both Gram-positive and Gram-negative with greater effect on Gram-negative more than standard compound in the first concentration. While compound "5d" showed activity against E. coli and E.Faecalis bacteria species, without antibacterial activity against Staphylococcus.aureus and Klepsiella.pneumonia, compound " $5 \mathrm{~b}$ " showed less antibacterial activity 
against Klepsiella and E.colicompare with compound 5 (c) that have good activity. Compound " $5 \mathrm{a}$ " and " $5 \mathrm{e}$ " did not show any antibacterial activity on all aerobic bacteria species. Compound " $5 \mathrm{~b}$ " and " $5 \mathrm{~d}$ " showed no effect on staphylococcus species. Compound " $5 \mathrm{~b}$ " showed some inhibition activity only in ( 0.5 and $0.25 \mathrm{mg} / \mathrm{mL}$ ) concentration with no activity with $(0.125 \mathrm{mg} / \mathrm{mL})$ concentration. Compound " $5 \mathrm{~d}$ " showed little activity only at the first concentration with no activity at second and third concentration. Compound " $5 \mathrm{e}$ " without any activity at all three concentrations. Compound " $5 \mathrm{c}$ " showed the best activity against anaerobic bacteria in compare to other compounds.

By review the chemical structure of synthesized compounds will notice that all compound "5a-e" have the same core structure and differ only in substitution group on para position of phenyl group that link to beta-lactam at C4 position, so any different in antibacterial activity is belong to this substitution, As a result the substituted compounds containing electron donating groups like methoxy functional group are showed more antibacterial activity than electron withdrawing group like nitro and chloride group ${ }^{10}$.

The lipophilicity (hydrophobicity) of a compound is essential physical property that effect on the passive movement of compound through membrane, so that the lipophilic feature of molecule play important role in antibacterial activity ${ }^{11-12}$. The octanol/water partition coefficient $C \log P$ is a measure of hydrophobicity/lipophilicity. The values of $C \log P$ were calculated using Chem Draw Ultra 8.0 software integrated with Cambridge Software (Cambridgesoft Corporation) obtained results shown in Table 4.

Molar refractivity (MR), the measure of steric factor, bulkiness of the molecule and its polarizability ${ }^{13-14}$ was also calculated using Chem Draw Ultra 8.0 software integrated with Cambridge Software (Cambridgesoft Corporation). the compounds having greater values of both $C$ Log $\mathrm{P}$ and molar refractivity showed better antimicrobial activity ${ }^{16}$. Depend on previous theoretical issue, compound " $5 \mathrm{c}$ " showed a high C Log P and higher molar refractivity (MR) that give its structure a good antibacterial activity.
These differences in cell wall structure can produce differences in the antibacterial susceptibility and some antibiotics which are effective against Gram-positive bacteria are found to be less or ineffective against Gram-negative bacteria ${ }^{15-13}$. the outer membrane of the Gram-negative bacteria is less permeable than the cell walls of Gram-positives. Therefore synthesized compound " $5 \mathrm{c}$ " showed better antibacterial activity towards Gram-positive bacteria specially (E.Faecalis) than Gram-negatives that made the movement of synthesized compound with high $C \log P$ through bacterial cell wall more easily, Also the substitution of $\mathrm{OCH}_{3}$ group at para position enhance the antibacterial activity ${ }^{16}$.

Table 4: $\log p$ and molar refractore of compound 5 derivatives

\begin{tabular}{ccc}
\hline Compound 5 & C Log P & Molar refractory \\
\hline a & 7.13 & 153.06 \\
b & 6.4 & 154.88 \\
C & 7.01 & 160.31 \\
d & 7.8 & 157.67 \\
e & 6.88 & 144.88 \\
\hline
\end{tabular}

By using ${ }^{1} \mathrm{H}-\mathrm{NMR}$ analysis to identification the synthesized compounds, all compound " $5 \mathrm{a}-\mathrm{e}$ " showed singlet band at range (4.02-4.35) $\delta \mathrm{ppm}$ belong to proton in $\mathrm{CH}_{2}$ group that adjacent to $(\mathrm{NH})$ with only one proton at nitrogen atom. Cyclic beta-lactam moiety has two proton in their structure, the first proton in cyclic bet-lactam observed at range (4.72 - 5.15) ppm, and present as doublet band due to effect of proton at adjacent $(\mathrm{CH})$ group, second proton of $(\mathrm{CH})$ group in cyclic beta-lactam moiety that bonded to chloride atom showed band range from (5.11-5.15) ppm higher than the first proton this due to proton near to an electronegative species are shifted "downfield" to higher $\delta$ values, all aromatic proton of 2,4,5-triphenyl imidazole observed above $6.71 \mathrm{ppm}$, with different splitting pattern depend on neighboring atom in same aromatic ring, most of them present at so close values, so appear on chart as overlap bands. compound " $5 \mathrm{c}$ " chart showed a strong singlet band at $3.76 \mathrm{ppm}$, this band belongs to proton atom at $\left(\mathrm{OCH}_{3}\right)$ that has zero proton at adjacent atom so appeared as a single band. Compound " $5 b$ " that have proton at $\mathrm{OH}$ group showed a single band at higher $\delta$ value $8.55 \mathrm{ppm}$, Signals for the proton in an $\mathrm{O}-\mathrm{H}$ bond are not affected by hydrogen on adjacent atoms so are not split. 


\section{CONCLUSION}

The newly synthesized compound "5a-e" showed a varying range of antibacterial activity. From the obtained results we can conclude that compound " $5 \mathrm{c}$ " displayed the best antibacterial activity against both aerobic and anaerobic bacteria, and this may belong to presence of electron donating group (methoxy group) that has a good lipophilicity and high molar refractivity in addition to substituted at para position, so it will be the better candidate for further study and investigation to get more efficient compound.

\section{ACKNOWLEDGEMENT}

Authorsare Thankful to Dr. Rahimjameel, Basrah University, Department of Pharmaceutical Chemistry, and University of Thi-qar, Department of Microbiology, for providing all efforts to complete this work.

\section{REFERENCES}

1. Shahzadi, S.; Noshin, Z.; Saira, R.; Rehana, S.; Jawad N.; \& Shahzad, N.; J. Nanomaterials., 2016, 6, 71.

2. Rustam, I. A.; Front. Microbiol., 2010, 1, 134.

3. Jin X., Zheng C.J.; Song M.X.; Wu Y.; Sun L.P. Eur. J. Med. Chem., 2012, 56, 203.

4. Roberta,J.; Worthington, M.; Christian, M.; Trends Biotechnol., 2013, 31(3), 177-184.

5. Starcevic, K.; Kralj, M.; Ester, K.; Sabol, I.; Grce, M.; Pavelic, K.; \& Karminski-Zamola, G.; Bioorg Med Chem., 2007, 15(13), 4419-26.

6. Arunkumar, S. S.; Research Journal of Chemical Sciences., 2015, 5(10), 67-72.

7. Zampieri, D.; Mamolo, MG.; Laurini, E.; Scialino. G.; Banfi, E.; \& Vio, L. Bioorg. Med. Chem., 2008, 16, 4516.

8. Asif, H.; Nadeem. S.; MD, S.; Yasmin, K.; \& Mohd, R. Acta Poloniae Pharmaceutica-Drug Research., 2011, 68(5), 657-663,

9. Subin, M. Za.; Mridula. R, Namy, G.; Mohammad, S. A.; Int. J. Pharm. Sci. Rev. Res., 2015, 30(1), January - February Article
39, 211-218.

10. Shailesh, P.Z.; Badmanaban, R.; Dhrubo, J. S.; \& Chhaganbhai, N. P, Journal of Applied Pharmaceutical Science., 2012, 02(07)202-208.

11. Holla, B.S.; Malini, K.V.; Rao, B.S.; Sarojini, B.K.; Kumari, N.S; Eur. J. Med. Chem., 2003, 38, 313.

12. Chohan, Z.H.; Sumrra, S.H.; Youssoufi, M.H.; \& Hadda, T.B. Eur. J. Med. Chem., 2010, 45, 2739.

13. Austel, V.; Kutter, Y.C.; Austel, E.; Marcel Dekker, V.; Eur. J. Drug Metab. Pharm., 1994, 3, 193.

14. D.A. Smith, Design of drugs through a consideration of drug metabolism and pharmacokinetics. Eur. J. Drug Metab. Pharm., 1994, 3, 193.

15. Maruyama, T.; Onda, K. M.; Hayakawa, N. S.; Takahashi, T.; Moritomo, H. T; Suzuki, T. Matsui.; Takasu, T. I.; Nagase, M. O. Med. Chem., 2009, 17, 3283.

16. Bipin, K. V.; Sunil, K.; Umesh K.; Savita, P.; \& Priti, A.; Indian J. Pharm. Biol. Res., 2017, 5(1), 1-9. 